\title{
ENSINO DE TRADUÇÃO: CULTURAS PEDAGÓGICAS
}

\author{
TRANSLATION TEACHING: PEDAGOGIAL CULTURES
}

Marileide Dias Esqueda*

\section{RESUMO}

Este trabalho busca mostrar os resultados de uma investigação realizada com professores de prática de tradução. Utilizando uma metodologia qualitativo-exploratória e de caráter descritivo, a pesquisa, dividida em duas fases, envolveu 12 cursos de graduação em Tradução. Iniciada em 2012, e utilizando questionários não estruturados, a proposta identificou o perfil acadêmico de professores de prática de tradução e suas rotinas pedagógicas. Em 2017, como forma de dar continuidade à investigação, e levando em consideração que os professores modificam ou estabilizam suas práticas com o passar dos anos (TARDIF, 2002; CHARLOT, 2009), a segunda fase deste estudo adotou uma proposta de investigação qualitativo-longitudinal (FLORES, 2003), com o objetivo de identificar, junto ao mesmo grupo de respondentes, as modificações que eles possam ter incorporado em suas salas de aula após cinco anos. Com base nos dados coletados, confirma-se a hipótese de que os estudos que buscam abdicar da abordagem centrada no professor, ou que são contra a pedagogia subjetiva e intuitiva de ensino (ARROJO, 1993; DARIN, 2001; COLINA, 2003 [2015]; KELLY, 2005; ECHEVERRI, 2008, 2015; KIRALY, 2016) não têm sido totalmente incorporados na sala de aula de formação de tradutores.

Palavras-chave: ensino de tradução; culturas pedagógicas nos estudos da tradução; professor de tradução.

\section{ABSTRACT}

This work seeks to show the results of an investigation carried out with translation trainers of practical courses. Using a qualitative-exploratory methodology, with a descriptive bias, the research, divided into two phases, involved 12 Brazilian Translation programs. Starting in 2012, and using unstructured questionnaires, the proposal identified the academic profile of translation trainers of practical courses and their pedagogical routines. In 2017, as a way of continuing the research, and taking into account that teachers modify or stabilize their practices over the years (TARDIF, 2002; CHARLOT, 2009), the second phase of this study adopted a qualitative-longitudinal methodology (FLORES, 2003), with the objective of identifying, with the same group of respondents, the modifications they may have incorporated in their classrooms after five years. Based on the collected data, it was possible to confirm the hypothesis that studies that seek to abdicate from the teachercentered approach, or that are against the subjective and intuitive pedagogy (ARROJO, 1993; DARIN, 2001; COLINA, 2003 [2015]; KELLY, 2005; ECHEVERRI, 2008, 2015; KIRALY, 2016) have had no effect in the translator training classroom.

Keywords: translation teaching; pedagogical cultures in translation studies; translator trainer.

\footnotetext{
* Universidade Federal de Uberlândia, Uberlândia (MG), Brasil. marileide.esqueda@ufu.br
} 


\section{PONTOS DE PARTIDA PARA UM ESTUDO SOBRE O ENSINO DE TRADUÇÃO}

Após emergirem decisivamente como um campo acadêmico em todo o mundo a partir da segunda metade do século passado, os Estudos da Tradução passaram a refletir, cada vez mais, sobre o ensino de tradução. Segundo Venuti (2017), a criação de mais de 350 programas que ofertam uma variedade de diplomas e títulos em todo o mundo, em nível de graduação e pós-graduação, englobando a prática e a pesquisa em tradução, ou combinando ambas, é uma realidade inquestionável. Para o autor:

O número de programas cresceu não apenas com a expansão do campo, mas também com o aumento considerável de organizações internacionais, com o contínuo surgimento de conflitos militares e políticos, e com o deslocamento em massa de pessoas, criando a necessidade urgente de tradutores e intérpretes. Ao mesmo tempo, em culturas multi- e bilíngues, a formação de tradutores é uma necessidade na medida em que a tradução se torna um acontecimento da vida cotidiana'. (VENUTI, 2017, p. 1, nossa tradução)

Em se tratando do contexto brasileiro, até os anos de 1990, havia poucos cursos de graduação em Tradução, e os Estudos da Tradução começavam a se firmar como uma área específica entre os que estudavam a linguagem. A partir desse ano, assim como no âmbito internacional, também houve significativa alteração nesse cenário. Para Rodrigues (2013):

[...] a institucionalização acadêmica da tradução em cursos de graduação gerou demanda por formação de docentes, tanto que em 1980 foi criada a pós-graduação lato sensu na USP e, em 1984, na Ibero-Americana. O passo seguinte foi a instituição da pós-graduação stricto sensu, o que nos leva à última das causas para a expansão [...]. Além disso, é necessário lembrar que em 1986 foi criada, no nível de Mestrado, a primeira área de concentração em tradução do país no Programa de Pós-Graduação em Linguística Aplicada da UNICAMP. Verifica-se, dessa maneira, que a somatória das atividades desenvolvidas na década de 1980 resulta na produção da década de 1990. (p. 58-59)

Atualmente, há mais de $15^{2}$ cursos superiores de formação de tradutores e intérpretes no Brasil e no mínimo dez instituições que ofertam a possibilidade de ingresso em programas de pós-graduação stricto sensu em tradução, ou como área de concentração ou linha de pesquisa (PAGANO e VASCONCELLOS, 2003, 2006;

1. The number of programs has risen not only with the expansion of the field but also with the steady increase of international organizations, the continual eruption of political and military conflicts, and the consequent displacement of mass populations, all of which create the urgent need for translators and interpreters. In multi- and bilingual cultures, meanwhile, translator training has long been a necessity insofar as translation is a fact of daily life.

2. http://emec.mec.gov.br/ 
GUERINI ${ }_{i}$ TORRES, COSTA, 2013). Nesse prisma, a crescente profissionalização na área torna cada vez mais premente a discussão sobre a formação de tradutores.

No que tange aos avanços científicos acerca do ensino da tradução, seguindo os novos paradigmas da educação de modo geral - com a consolidação, nos anos de 1990, de abordagens de ensino centradas no aluno (VYGOTSKY, 1998), em oposição à aula centrada no professor como detentor único do conhecimento -, a didática da tradução, desde o final do século XX, partiu do ensino convencional em que o professor atuava como transmissor da tradução certa, com forte apelo à exatidão da transferência linguística, conforme criticam Arrojo (1993) e Darin (2001), e passou a demandar objetivos claros e sistematizados de ensino (DELISLE, 1993). Buscou incorporar, em seguida, a epistemologia socioconstrutivista (KIRALY, 1995, 2000), as abordagens autônomas e de autoformação do tradutor (ROBINSON, 1997 [2002]), o ensino por competências e a abordagem por tarefas (HURTADO ALBIR, 1999; GONÇALVES, 2015). Também insistiu na formação centrada nas especificidades técnicas de cada gênero e tipologia textuais, a partir de modelos funcionalistas de análise textual (NORD, 1991), em paralelo à discussão concernente aos impactos positivos e negativos das novas tecnologias aplicadas à tradução e, em especial, dos sistemas de memória de tradução (PYM, 2003; BOWKER, 2005, 2015). Complementarmente, chegou aos modelos experimentais de aprendizagem, ensejando a união entre sofisticados softwares de análises processuais e cognitivas, com os protocolos verbais e registros de acionamentos de mouse e teclado (TIRKKONNEN-CONDIT, 1989, 1991; ALVES, 1997, 2003).

A partir desses estudos, a didática da tradução vem buscando abdicar da abordagem centrada no professor $\mathrm{e}$, na via oposta, valorizar um conjunto de especificidades que norteiam qualquer ato de tradução como atividade autoral e condicionada a uma série de influências contextuais e históricas. No entanto, para Echeverri (2015) ${ }^{3}$, o vazio metodológico encontra-se na pedagogia da tradução, isto é, no estudo das interações da sala de aula de formação de tradutores. $\mathrm{O}$ autor afirma que as noções sobre pedagogia e didática são normalmente utilizadas de forma indiscriminada. Para ele, a pedagogia se interessa pela natureza e qualidade das interações em sala de aula, ao passo que a didática consiste no estudo daquilo que deveria, idealmente, ocorrer nesse ambiente.

Assim, é considerando esse universo de pesquisa acerca da pedagogia da tradução que este trabalho se insere. Visando contribuir com as pesquisas

3. Echeverri (2015) toma como base a distinção entre didática e pedagogia do trabalho de FIOLA, M. (2003). Prolégomènes à une didactique de la traduction professionnelle, META. 48, (3), pp. 336-346. 
relacionadas a essa temática, o estudo que será aqui relatado encontra inspiração no que argumenta Vygotsky (1998), de que quanto mais se discute a didática e a formação de alunos, mais se deve ampliar as investigações sobre os professores e suas salas de aula. Portanto, o foco recai sobre os saberes ${ }^{4}$ do docente de prática de tradução e seu fazer diário em sala de aula, proposta ainda escassa no Brasil, cujo único registro de publicação similar que se tem conhecimento é o de Darin (2001).

Esta pesquisa foi estruturada de modo a compreender o que ocorre no contexto da sala de aula de ensino de tradução e como se dá o desenvolvimento profissional do docente ao longo de sua carreira, por meio da análise dos (complexos) fatores pessoais e contextuais que influenciam sua atuação e seu crescimento.

\section{RECORTE DAS CONTRIBUIÇÕES À PEDAGOGIA DA TRADUÇÃO}

Tradicionalmente, segundo Kelly (2005), a maioria das aulas de tradução, principalmente aquelas anteriores à década de 1980, limitava-se a solicitar aos alunos a tradução (muitas vezes oral) de um texto jornalístico ou literário, sem que o aluno tivesse tempo para prepará-la. Em seguida, o professor ditava a tradução "correta", que passava a servir como um modelo, atestando a falta de qualidade profissional das traduções dos alunos e frustrando-os na tentativa de aprender a traduzir, como se o aluno aprendesse a traduzir traduzindo. Para a autora, "essa abordagem era essencialmente antipedagógica, e, com certeza, extremamente frustrante para os alunos $^{\prime \prime}$ (p. 11, nossa tradução).

Arrojo (1993) também concorda que outorgar ao professor o poder de "saber" traduzir e supostamente "possuir" as soluções corretas para os problemas de tradução se baseia na possibilidade de uma transferência impessoal de um conjunto de significados privilegiados de professor para aluno e de uma geração para outra. Para a autora, a pedagogia idealizada pela tradição logocêntrica também se funda a partir do desejo (humanamente impossível) do apagamento da linguagem e de uma traduzibilidade exaustiva, associando o ensino à frustração e ao fracasso, cuja "meta única é a conquista do impossível" (ARROJO, 1993, p. 137), de uma onipotência que possa produzir uma tradução livre de qualquer "erro" e que sobreviva à passagem do tempo e às mudanças de contexto.

4. Pimenta (2016) tem preferência pela utilização do termo "saberes", por argumentar que o termo "competências" pode contribuir para a prevalência de um paradigma investigativo que não pressupõe o desenvolvimento contínuo e a formação reflexiva do professor, mas, ao contrário, fortalece o ensino utilitarista e mercadológico.

5. This approach to training was essentially a pedagogical, and of course extremely frustrating for students. (KELLY, 2005, p. 11) 
Buscando examinar o cenário de ensino e aprendizagem da tradução em âmbito universitário, Darin (2001) realizou uma pesquisa com professores de cursos de graduação em Tradução, com o objetivo de investigar as estratégias de ensino adotadas nos cursos voltados para a formação de tradutores. Segundo a autora:

Apesar do tom aparentemente seguro e "esclarecedor" das respostas, percebo uma falta de consenso entre os educadores sobre os parâmetros utilizados para a seleção dos textos; as escolhas recaem em critérios subjetivos, que não parecem ter sido alvo de discussão com colegas. (p. 70)

Os dados coletados pela pesquisadora revelam que os docentes agregam à sua prática dinâmicas pouco sistematizadas, tais como elaboração de glossários, apresentação de seminários, leitura e preparação de textos "em casa" e tradução de um trecho em sala, apresentação de paineis com os problemas de tradução, opções e soluções tradutórias, aula exposivita sobre o tema, cotejo entre traduções publicadas, dentre outros. A partir dos relatos dos respondentes, Darin (2001) chega à seguinte conclusão com relação à estrutura pedagógica típica de uma aula de tradução em contexto brasileiro:

[...] os alunos recebem um texto de partida que devem traduzir individualmente, em casa, e trazer para discussão em sala, onde, às vezes em pequenos grupos, mas sempre, em algum momento, em "grupão", debatem suas propostas sob a orientação do professor. É ele quem centraliza e controla o processo, e a praxe é que leia um trecho do texto a traduzir e solicite a um aluno que leia sua tradução, a partir da qual serão feitos comentários; o aluno selecionado deve justificar sua opção, mas é o professor que se responsabiliza pela avaliação das traduções e oferece as soluções quando há impasses. (p. 71; destaque da autora)

A autora explica que, nas respostas fornecidas pelos entrevistados, percebese que o professor, apesar de propor atividades que procurem desenvolver a capacidade dos alunos de forma a torná-los agentes de seu processo de aprendizagem da tradução, "acaba por revelar a crença de que há respostas definitivas, objetivas e fiéis aos textos de partida" (p. 72).

A pesquisa ainda mostra que quando solicitados a realizar uma descrição detalhada dos procedimentos pegagógicos adotados, os docentes defendem uma "análise minuciosa do texto original", que, para Darin (2001), implica conceitos de leitura e tradução muito limitados e bastante nocivos ao aprendiz, já que não se pode supor que um texto seja passível de total objetividade e univocidade de sentido.

Outro exemplo destacado pela autora quanto aos procedimentos pedagógicos adotados pelos docentes diz repeito à avaliação da tradução em sala de aula: 
Uma ideia um tanto ingênua de tradução pode ser lida na descrição de uma estratégia de ensino, citada por uma professora: "comparação das traduções feitas, quando um "acordo coletivo' é alcançado e possibilidades finais de tradução são editadas". Privilegiar um acordo coletivo é descartar diferenças e preferências individuais a fim de enfatizar a melhor tradução, que o futuro tradutor anotará em seu rascunho. Em minha experiência como professora de Prática de Tradução, o convívio de diversas opções tem por finalidade dar ao graduando a possibilidade de exercitar sua capacidade crítica e, devo esclarecer, é algo que os próprios alunos logo aprendem a reivindicar com veemência. (p. 73)

Os dados coletados por Darin evidenciam que as estratégias pedagógicas comumente empregadas pelos docentes, além de não possuírem uma diretriz predominante, implicam a busca por uma correlação ideal entre original e tradução, principalmente quando a docente mencionada na citação anterior busca um "acordo coletivo em sala" para se chegar a uma possibilidade final de tradução.

Além da questão do ensino da tradução estar atrelado à concepção de língua subjacente ao conceito do que seja traduzir, Gonçalves e Machado (2006) ainda apontam que:

No Brasil, a divergência entre as orientações didáticas ou a ausência de uma diretriz predominante para a formação do tradutor é também evidente. Os tradutores ou pesquisadores da área que tenham participado de um ou vários dos oito Encontros Nacionais de Tradutores, ocorridos nos últimos anos, devem ter observado uma tendência de polarização entre seus pares em relação à forma como se define a natureza da competência do tradutor e como se postula o seu desenvolvimento. Por exemplo, uma divergência bastante recorrente, tanto no universo acadêmico quanto profissional, refere-se à diretriz didático-metodológica a ser adotada na formação do tradutor e pode ser expressa pela dicotomia treinamento prático (automatização/ desenvolvimento de conhecimentos procedimentais - saber como) versus reflexão teórica (conscientização/ desenvolvimento de conhecimentos declarativos - saber o quê). (p. 48)

As práticas pedagógicas criticadas por Arrojo (1993), Darin (2001), Kelly (2005) e Gonçalves e Machado (2006), marcadas por um ensino centrado no professor e associado à reprodução de um "original" que deve ser "preservado para que não perca suas propriedades essenciais", parecem vigorar desde há muito tempo. Para Echeverri (2015):

A despeito de seus significativos progressos em vários aspectos, a formação de tradutores mostra certo grau de estagnação em termos de conhecimento pedagógico. Um olhar sobre as disciplinas de prática de tradução revelaria que, com exceção de alguns poucos iconoclastas, as práticas de ensino dentro das salas de aula evoluíram muito pouco nos últimos $70 \operatorname{anos}^{6}$. (p. 9; nossa tradução)

6. A pesar de haber realizado progresos significativos en varios aspectos, la formación de traductores evidencia cierto grado de estancamiento en lo referente a los conocimientos pedagógicos. Una mirada al interior de los cursos prácticos de traducción revelaría que, con la excepción de unos pocos iconoclastas, las prácticas docentes al interior de las aulas de clase han evolucionado muy poco en los últimos setenta años. 
O autor afirma que la performance magistrale, ou conferência magistral, como será aqui referida, que está presente há anos no ensino de tradução como uma fórmula pedagógica (LADMIRAL, 1979), torna as soluções dos problemas tradutórios, que surgem nos textos trabalhados em sala de aula, dependentes da versão autorizada do professor e ao mesmo tempo limita a aprendizagem do aluno a uma instância de escutar e tomar notas. Echeverri (2015) também explica que cada geração de professores recebe as heranças de uma tradição e cultura que contribuem para a perpetuação de certas ações pedagógicas. Para o autor, sem a formação pedagógica explícita, a partir da qual os professores poderiam ser expostos a progressos das ciências da educação e do ensino na área, o professor de tradução recorre apenas à sua experiência pessoal, à sua própria história como tradutor ou como aluno, repetindo as práticas de seus professores, deixando de guiar-se por uma base de conhecimentos relativos aos avanços na formação de tradutores compartilhados pela comunidade científica.

Kiraly (2016) igualmente afirma que o ensino formal da tradução, baseado na epistemologia do empirismo-racionalismo, ainda é demasiadamente dependente da intuição dos professores sobre o que os alunos devem saber e aprender. Segundo o autor:

$\mathrm{Na}$ ausência de programas de formação para professores de tradução, esse fórum acadêmico fundamental carece de discussão aprofundada sobre a epistemologia pedagógica, práticas de sala de aula ou testes de procedimentos entre a comunidade de formadores de tradutores. Sem um verdadeiro campo de "formação do tradutor", afirmo que, não pode haver praticamente nenhuma identificação de princípios comuns, somente trabalho colaborativo mínimo acerca de abordagens baseadas em princípios, e não há avaliação contínua e sistemática das práticas de ensino. É verdade que apresentações em conferências, oficinas, artigos em periódicos e outras publicações geram reflexões consideráveis para a comunidade de formadores de tradutores, mas a criação de programas acadêmicos qualificados destinados aos professores de Tradução é ainda um grande anseio. (p. 229)

$\mathrm{Na}$ perspectiva de Kiraly (2016), o problema da ausência de programas acadêmicos direcionados à formação de professores de tradução - que precisam que recorrer a suas próprias intuições e à chamada abordagem do senso comum -, tem sido o fulcro da questão.

Compartilhando as mesmas inquietações, Colina (2003 [2015]) afirma que:

Várias universidade e faculdades hoje mostram um crescente interesse na tradução como uma área na qual se desenvolvem novos cursos, cursos de graduação, cursos técnicos, e, às vezes, disciplinas específicas de tradução, geralmente ofertadas em departamentos de línguas estrangeiras. Muitas dessas instituições de ensino, porém, enfrentam um sério problema: falta de critérios pedagógicos e metodológicos consistentes e claros de como abordar as questões relacionadas ao ensino da tradução e ao planejamento de cursos. (p. 30) 
Para a autora, que trata da realidade da formação de tradutores nos Estados Unidos, a situação piora quando os responsáveis pelos cursos de tradução são professores de línguas, muitos dos quais foram expostos à tradução apenas como um exercício em cursos de línguas estrangeiras, e não têm experiência ou formação na área como uma atividade profissional. Para Colina (2003 [2015]), no melhor dos casos, eles desesperadamente se voltam à comunidade profissional e/ou acadêmica como solução para uma situação pedagógica difícil. No pior dos casos, permanecem desinformados e ensinam tradução como eles mesmos aprenderam.

Assim, é levando em consideração os problemas e desafios relacionados à pedagogia da tradução que este estudo busca investigar a sala de aula de ensino de tradução, especificamente no Brasil.

Trata-se de explicitar os resultados de uma pesquisa qualitativo-exploratória que, iniciada em 2012, utilizou questionários não estruturados para identificar o perfil acadêmico de professores de prática de tradução e suas rotinas pedagógicas em contexto brasileiro. Em 2017, como forma de dar continuidade à investigação, e levando em consideração que os professores modificam ou estabilizam suas práticas com o passar dos anos (TARDIF, 2002; CHARLOT, 2009), a segunda fase deste estudo adotou uma proposta de investigação qualitativo-longitudinal (FLORES, 2003), com o objetivo de identificar, junto ao mesmo grupo de respondentes, as modificações que eles possam ter incorporado em suas salas de aula após cinco anos, bem como os conteúdos que para eles se mostram mais difíceis e mais fáceis de serem ensinados.

\section{A PESQUISA SOBRE O PROFESSOR DE TRADUÇÃO E SUA CULTURA PEDAGÓGICA}

Desde sua concepção em 2012, a pesquisa que ora se apresenta busca corroborar a hipótese de que as proposições teóricas, principalmente aquelas que se mostraram contra a conferência magistral, ou pedagogia centrada no professor, discutida desde há muito no ensino da tradução (ARROJO,1993; DARIN, 2001; COLINA, 2003 [2015]; KELLY, 2005; GONÇALVES e MACHADO, 2006, KIRALY, 1995, 2000, 2016; ECHEVERRI, 2008, 2015), não têm sido incorporadas em sala de aula a ponto de darem lugar a uma nova concepção sobre o ensino de tradução.

Iniciada em 2012 e registrada no Comitê de Ética Nacional da Universidade Federal de Uberlândia, à qual pertence a autora deste estudo, sob o Protocolo e Registro da Plataforma Brasil no 00676013.1.0000.5152, esta pesquisa teve como 
proposta identificar os saberes do professor de prática de tradução por meio de seu fazer diário, almejando o descortino das práticas docentes em ambiente real de sala de aula. Assim, foram traçados os seguintes objetivos específicos primários: 1) identificar o perfil dos docentes de diferentes instituições públicas e privadas de ensino superior que ofertam o curso de graduação em Tradução, principalmente no que tange à sua formação acadêmica, área de atuação, pesquisa e aperfeiçoamento; 2) categorizar e discutir como os professores definem seu modelo de saberes e como esse se reverte em ações no fazer diário da sala de aula de prática da tradução; 3) analisar quais fatores se mostram determinantes para o desdobramento dos saberes e perfis dos professores de tradução em contexto brasileiro.

Foram incluídos, nesta primeira fase da pesquisa, os professores universitários que ministram aulas práticas em cursos de graduação em Tradução em universidades públicas e privadas, muito embora alguns desses professores também ministrem disciplinas teóricas ligadas à área. Foram primeiramente verificadas as instituições que ofertam o curso através do site www.emec.gov.br, a partir das seguintes entradas em seu sistema de busca: "Tradução"; "Tradutor"; "Tradução e Interpretação"; "Tradutor e Intérprete"; "Letras Habilitação em Tradutor"; "Letras Tradução". Essa varredura no site resultou em 12 instituições brasileiras que ofertam cursos de Tradução, tendo sido recrutados de um a dois professores de tradução de cada uma dessas instituições, totalizando um universo de seis professores de instituições públicas e sete de instituições privadas (Tabela 1). Os professores-sujeitos da pesquisa foram entrevistados por meio de comunicação via correio eletrônico, sendo que um deles foi entrevistado pessoalmente ${ }^{8}$. Foram excluídos os professores que ministram aulas nos cursos de graduação em Letras, mesmo aqueles que ofertam disciplinas sobre tradução nessa carreira universitária, que, futuramente, poderão ser inclú́dos em uma pesquisa mais abrangente.

7. Ressalta-se, por conhecimento pessoal da autora deste estudo, haver a existência de outros cursos de graduação em Tradução no país, mas que não foram contemplados nesta pesquisa por não estarem registrados, no ano de 2012, no site www.emec.gov.br. Também foram excluídos os docentes de cursos de Tradução e Interpretação em Libras.

8. Como toda pesquisa de cunho qualitativo envolvendo seres humanos pode apresentar prejuízo aos sujeitos, os riscos desta investigação, embora potenciais, consistiram em gerar conhecimento, ainda desconhecido e pouco explorado em pesquisas anteriores, quanto ao perfil e à atuação de docentes de cursos de graduação em Tradução no país. Buscou-se minimizar o risco de identificação do sujeito por meio da explicitação de dados em forma de enumeração geral, tratando das respostas dos respondentes de maneira genérica e numérica. Por outro lado, os benefícios individuais e coletivos podem ser os de conhecer os saberes e os perfis dos docentes que atuam nos cursos brasileiros de Tradução, traçar os tipos de relações entre ensino e aprendizagem que se tem estabelecido no país e almejar novas perspectivas para o ensino na área. 
Tabela 1. Universo de investigação

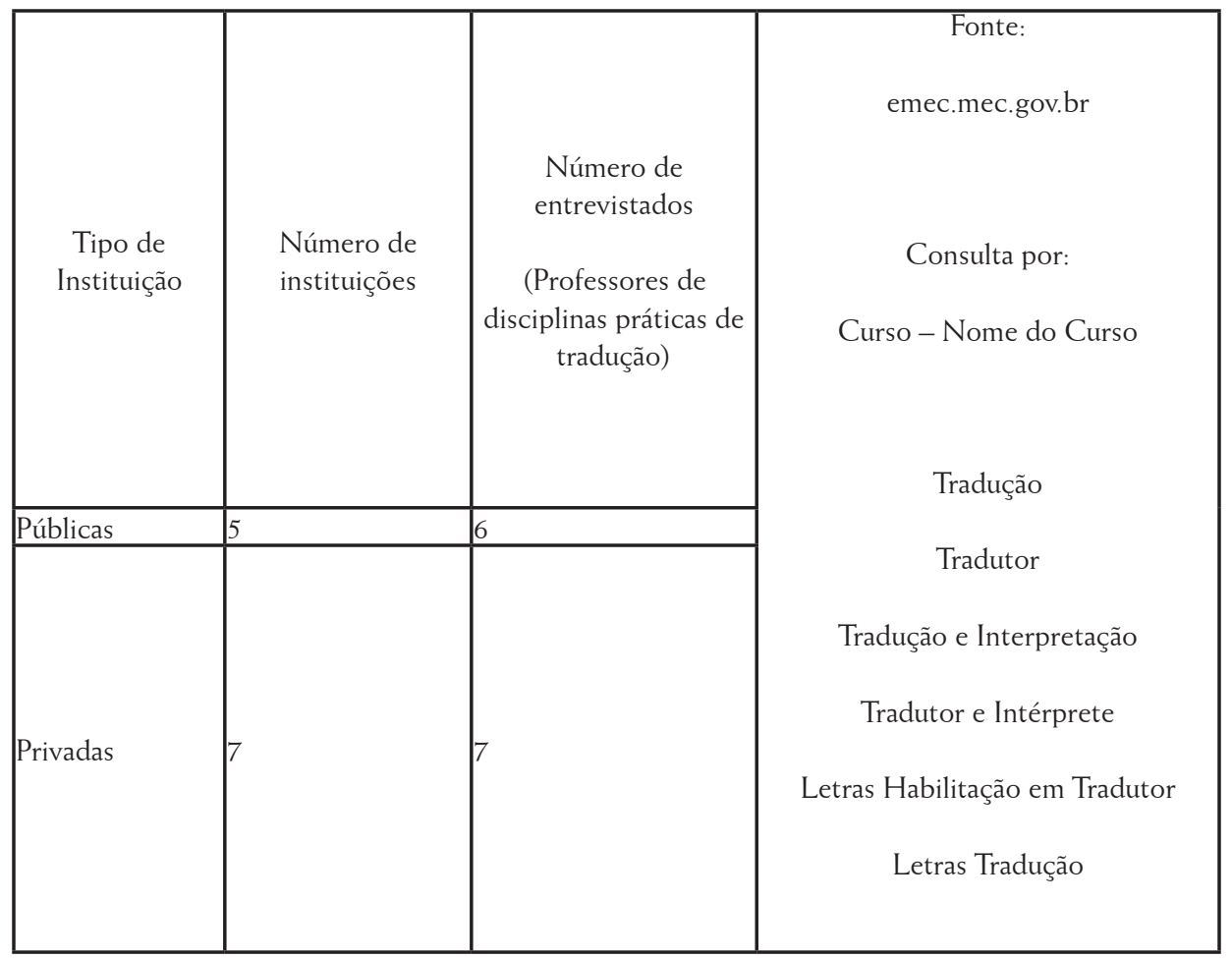

Fonte: a autora

A Figura 1 mostra a localização das instituições que tiveram seus docentes entrevistados.

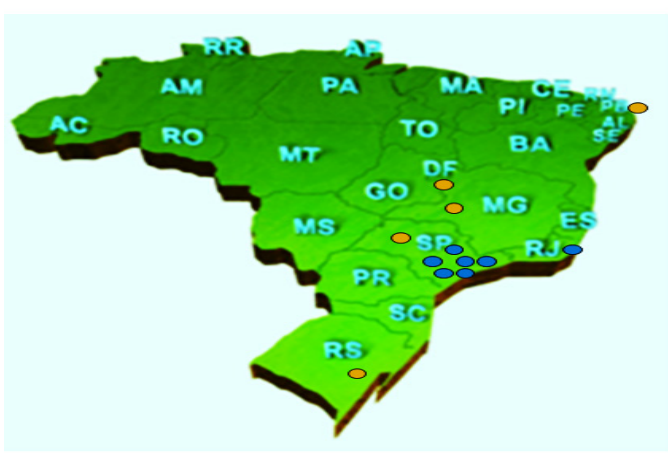

CONTEXTO DE INVESTIGAÇÄO

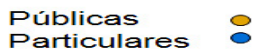

Figura 1. Mapa da localização dos contextos de investigação

Fonte: a autora 
Os professores foram informados a respeito dos objetivos da proposta e concordaram em participar da pesquisa por meio da assinatura do Termo de Consentimento Livre e Esclarecido (TCLE). Como forma de preservar a identidade dos sujeitos, cada professor entrevistado corresponde à letra " $\mathrm{P}$ " acompanhada de um número de 1 a 13 .

Conforme mostra a Tabela 1, a pesquisa contou com a participação de 13 docentes, que receberam dois questionários não estruturados, respectivamente Q1 (Questionário 1): Perfil dos docentes; Q2 (Questionários 2): Questões relativas à prática docente.

A aplicação do Q1 visou colher informações pessoais, formação acadêmica e experiência profissional dos docentes. O Q2 teve como objetivo verificar as disciplinas ministradas pelo professor, os principais procedimentos pedagógicos que utiliza em sala de aula para apresentação e avaliação dos conteúdos ministrados, quais fatores influenciam sua prática docente, o que é ser um bom professor de tradução, e, por último, como o professor delineia seus saberes docentes. Os questionários foram estruturados com base em Darin (2001) e Esqueda e Oliveira (2013). A segunda fase da pesquisa e os objetivos secundários serão explicitados no tópico 3.2 .

\subsection{Resultados da primeira fase (2012): perfis e pedagogias dos docentes de tradução}

Como na maioria das pesquisas sobre professores, a predominância nesse grupo é do sexo feminino, sendo que dos 13 entrevistados, dois são do sexo masculino. Algumas pesquisas na área de educação têm mostrado que o magistério tornou-se uma profissão feminina. $O$ fato de a maioria dos professores serem mulheres produz marcas da presença feminina na caracterização dos profissionais, formas de ensino, relações estabelecidas entre os atores que dão materialidade à escola. Embora não faça parte do escopo deste trabalho avaliar a feminização do ensino da tradução, vale ressaltar que, de acordo com Assunção (1996), Carvalho (1999), Tanuri (2000), Giorgi et al. (2010), o conceito de "feminização do magistério" revela uma associação entre escola e maternidade, como continuidade do lar sob a orientação e coordenação das mulheres.

Dos 13 entrevistados, com idade média entre 34 e 61 anos, sete possuem graduação em Letras e seis em Tradução. Com relação à formação em nível de mestrado, seis possuem mestrado em Tradução, dois em Literatura, dois em Ensino de Línguas, um em Análise do Discurso, um em Semiótica e outro em Linguística. Com relação à formação em nível de doutorado, quatro dos entrevistados não 
possuem o título (segundo os dados obtidos em 2012), seis possuem doutorado em Tradução, um em Literatura, um em Semiótica e um em Fonoaudiologia. Dois docentes afirmam ter pós-doutorado em Tradução em universidades do exterior. A média de experiência com o ensino de tradução é de 14 anos dos docentes das instituições particulares, sendo que P6 possui 30 anos de experiência no ensino de tradução; e de aproximadamente quatro anos dos docentes pertencentes às instituições públicas.

Ainda com relação ao Q1, 100\% dos docentes das instituições particulares (sete docentes) afirmaram ter experiência profissional como tradutores ou intérpretes, tendo como clientes os colegas do próprio ambiente acadêmico em que atuam, editoras e empresas. Um deles é tradutor público e intérprete comercial. No caso dos seis docentes das instituições públicas, dois afirmaram nunca terem traduzido. Os outros quatro prestam serviços de tradução a clientes do próprio ambiente acadêmico em que atuam e às editoras. Um deles é tradutor público e intérprete comercial.

Os respondentes relataram, em sua maioria, que frequentam os eventos científicos da área, sendo os mais citados os congressos da Associação Brasileira de Pesquisadores em Tradução (ABRAPT), da Associação Brasileira de Linguística (ABRALIN) e do Grupo de Estudos Linguísticos (GEL). Três dos respondentes relataram nunca ou raramente participarem de eventos científicos. $50 \%$ dos respondentes relataram participar de fóruns virtuais e grupos de pesquisa, sem especificar, no Q1 ou Q2, como as participações oriundas desses fóruns ou grupos agregam valor à docência. Quando solicitados a responder se faziam parte de alguma associação de tradução ou de instituições ligadas à classe de tradutores, $84 \%$ dos entrevistados não são membros de associações ligadas à área de tradução.

Pode-se depreender dos dados coletados no Q1 que os 13 professores entrevistados têm perfil diversificado em relação à área de formação, idade e ao tempo de docência no ensino de tradução, o que poderá, a partir dos dados do Q2 apresentados a seguir, evidenciar a ausência de uma prática docente equalizada para o ensino de tradução e a não incorporação dos avanços teóricos e científicos à sala de aula.

Com relação ao Q2, as descrições gerais feitas pelos professores quanto à rotina pedagógica e aos procedimentos metodológicos que implementam em seus contextos, tem-se que:

- as aulas são expositivas e realizadas em laboratório de informática,

- o professor contextualiza o assunto; 
- os gêneros textuais são apresentados pelo professor antes da realização das traduções;

- há exposição e discussão sobre o conteúdo do texto que será traduzido;

- após as orientações, a tradução é encomendada como atividade extraclasse, e o aluno deve finalizá-la fora do contexto da sala de aula,

- em aula posterior, os alunos leem excertos do texto traduzido para o professor e colegas; alguns alunos são sorteados para a apresentação oral de suas traduções;

- o professor discute as opções dos alunos, avaliando a consistência terminológica do texto;

- há utilização de referenciais teóricos com o intuito de diminuir o percentual de dúvidas sobre o que é uma tradução fiel.

Ainda com relação aos procedimentos pedagógicos, $\mathrm{P} 9$ e P13, ambos docentes de instituições públicas, mencionaram haver a utilização de sistemas de memória de tradução na rotina de elaboração das traduções em sala de aula. P9 também afirmou que, mesmo utilizando tais sistemas, não se dedica ao processo de revisão final da tradução durante as aulas. P6 afirmou escolher os textos a serem traduzidos por temas ou por números de palavras (de 280 a 350 palavras em disciplinas práticas introdutórias; e de 350 a 500 palavras em disciplinas práticas avançadas). P11, que ministra todas as disciplinas de prática de tradução na instituição pública à qual pertence, quais sejam, prática da tradução de textos acadêmicos, comerciais, jurídicos e literários, afirmou solicitar, em média, dez páginas a serem traduzidas, sendo que os alunos traduzem metade em sala e metade como atividade extraclasse.

A rotina pedagógica relatada pelos entrevistados revela semelhança com as discussões implementadas por Arrojo (1993), Darin (2001), Kelly (2005), Gonçalves e Machado (2006), Colina (2003 [2015]), Echeverri (2008, 2015), que atestam a inexistência de consenso entre os educadores com relação aos critérios norteadores da formação do tradutor, ou seja, os docentes utilizam critérios subjetivos e aparentemente arbitrários para a seleção dos textos a serem traduzidos pelos alunos e usam a conferência magistral como fórmula pedagógica predominante, a partir da qual o professor, após encomendar a tradução, busca avaliar a consistência e o conteúdo correto dos textos traduzidos.

Os docentes entrevistados mostram, de maneira geral, que adotam atividades convencionais, nas quais se realizam a leitura do texto original, a sua tradução preliminar de forma oral, a elaboração da tradução pelos alunos em intervalo de tempo pré-estipulado, durante o qual os alunos devem aprender a traduzir traduzindo e, por último, a posterior verificação das opções de tradução junto a todos os alunos; outros professores agregam a essa prática outras atividades que, no 
entanto, são implementadas à rotina pedagógica de maneira isolada e assistemática. Vale ressaltar que apenas quatro dos 13 docentes afirmaram utilizar aportes teóricos nas disciplinas de prática de tradução, o que parece fazer prevalecer a dicotomia entre teoria e prática da tradução entre os docentes (ARROJO, 1998), distanciando os alunos da postura reflexiva e autônoma (KIRALY, 2000).

Com relação aos critérios de avaliação das traduções, os docentes apontaram a utilização de:

- pseudônimos para que as traduções sejam avaliadas às cegas;

- paratextos para o registro de justificativas quanto às escolhas tradutórias feitas pelos alunos;

- feedback individual;

- chamada oral;

- tradução autocomentada para que o aluno tome ciência de suas escolhas;

- provas teóricas e práticas, com elaboração de glossários; e

- atribuição de metade dos pontos por traduções feitas em sala e outra metade pelas traduções feitas fora desse ambiente.

Embora já se encontrem vestígios de uma avaliação formativa de tradução nesses relatos (COLINA, 2003 [2015]; KELLY, 2005), em que as justificativas dadas pelos alunos com relação à adoção de estratégias de tradução são incorporadas ao sistema de avaliação, os professores entrevistados, em geral, centralizam e controlam o processo de aprendizagem, responsabilizando-se pela avaliação das traduções e oferecendo soluções diante de impasses. Critérios de avaliação centrados no aluno ou autoavaliação não foram relatados pelos respondentes nessa fase da pesquisa. Para Echeverri (2015), a autoavaliação no ensino de tradução leva à formação de aprendizes mais autônomos.

Quanto aos fatores que mais influenciam/influenciaram as práticas adotadas pelos docentes em sala, dos 13 docentes entrevistados, oito responderam que o que mais influenciou e influencia suas atuações como professores de tradução é o fato de serem tradutores e "saberem do que estão falando" [sic]. Um docente mencionou que a troca de experiências com os colegas e o interesse em aprender mais é o que o faz querer estar em sala de aula. Outro respondente afirmou que o fato de trabalhar em uma instituição que disponibiliza recursos tecnológicos é o que mais influencia sua atuação como docente, ressaltado por P13 em várias de suas respostas. Um docente afirma ter sofrido influência de bons professores e que, portanto, é o que o motivou ser professor. Um docente respondeu que o que o fez escolher a carreira de professor de tradução foi o fato de gostar muito de sua língua materna, a língua 
portuguesa. Outro respondente relatou que sua escolha pela carreira deu-se por ter sido convidado para o cargo, sem apresentar maiores detalhes ou quaisquer outras motivações. Entre a maioria dos docentes, prevalece a concepção de que ser tradutor profissional é o que confere ao docente uma atuação mais sólida e, por consequência, autoridade para avaliar seus alunos.

No que tange à forma como os docentes de tradução definem seus saberes, foi possível categorizar seus comentários em três dimensões:

1. Dimensão linguística e teórica: os respondentes afirmaram, majoritariamente, que todo professor de tradução deve ser tradutor, o que pressupõe o conhecimento linguístico e o conhecimento acerca dos diversos gêneros textuais e suas características.

2. Dimensão profissional e mercadológica: para os entrevistados, o professor deve dominar ferramentas e ter experiência de mercado. Segundo P2: "é comum professores darem informações erradas sobre o mercado; o professor, sem o lado prático, apresenta falha na condução das aulas [sic]"; outro docente observou que "o professor que pratica a modalidade que leciona transita melhor por esta e não revela utopias [sic]".

3. Dimensão social: os respondentes mencionaram que o professor de tradução deve saber ouvir; saber explicar e transmitir sua experiência aos alunos; saber aceitar as diferenças; ter carisma; ter boa convivência com os alunos; gostar de lecionar; ser sincero com a relação à remuneração que o mercado oferece; curioso; inquieto; interessado; atento; deve perceber as limitações dos alunos e saber saná-las na hora certa.

Quando indagados sobre o que é ser um bom professor de tradução, os respondentes apontaram que é aquele que:

- se mantém atualizado com relação às práticas do mercado;

- esclarece os malefícios das crenças sobre tradução;

- corrige os erros, mas também aponta os aspectos positivos das traduções dos alunos;

- aceita as diversas opções de tradução trazidas pelos alunos;

- tem autoridade para corrigir os alunos por ser um tradutor reconhecido; para P6, o professor que é tradutor premiado (no setor editorial) sabe dominar a sala de aula; 
- auxilia o aluno na busca pela autonomia através da construção do conhecimento empírico sobre onde buscar soluções;

- percebe as limitações dos alunos;

- é capaz de fornecer aos alunos atividades variadas com textos de diferentes gêneros;

- revisa o texto com os alunos, verificando se estão progredindo ou se continuam cometendo os mesmos erros.

Faz-se pertinente ressaltar que, em estudo sobre as crenças de ingressantes de um curso de graduação em Tradução de uma universidade pública, Esqueda e Oliveira (2013) verificaram que, para a maioria dos alunos, um bom professor de tradução é aquele que tem amplos conhecimentos de gramática das línguas envolvidas no processo de tradução e das técnicas de tradução. As concepções dos alunos do que seja um bom professor de tradução não estão equiparadas às visões dos professores, pois apenas dois, dos 13 docentes entrevistados, mencionaram que um bom professor de tradução deve ter amplos conhecimentos linguísticos. Nenhum professor mencionou o domínio das técnicas de tradução como pressuposto para uma boa atuação docente, conforme esperado pelos alunos.

Apesar do reduzido universo de respondentes, as informações coletadas nos Q1 e Q2 podem servir como um primeiro retrato de como os professores descrevem suas rotinas pedagógico-metodológicas e como definem seus saberes docentes.

Observa-se, em linhas gerais, a ausência de diretrizes pedagógicometodológicas comuns na sala de aula de tradução, não havendo consenso sobre o modo como os textos poderiam ser abordados e traduzidos. No que concerne aos saberes do docente de tradução, observa-se que os respondentes privilegiam a competência profissional e mercadológica do professor, que estaria atrelada a apenas um dos saberes docentes retratados por Pimenta (2016), isto é, os saberes da formação profissional. Os entrevistados não revelaram em seus comentários outros saberes docentes tais como o pedagógico, curricular e experiencial, tampouco citaram a articulação entre eles, revelando uma atuação ainda pouco preocupada com a didática e a pedagogia e mais interessada no saber prático (formação profissional).

Para Tardif (2002) e Pimenta (2016), os saberes da docência envolvem: a) os saberes profissionais, isto é, os específicos do profissional e dos conhecimentos da área de sua especialidade; b) os saberes pedagógicos, que abrangem a construção de ações pedagógicas em sala de aula, a partir das necessidades dos alunos; c) os saberes curriculares, relativos à transformação dos conteúdos em disciplinas e programas de ensino; e d) os saberes experienciais, que são mobilizados a partir 
do universo de experiências (pessoais e profissionais) do professor, exigindo da atividade uma constante reflexão e reconfiguração. Pimenta (op.cit.) enfatiza ainda que a fragmentação entre os diferentes saberes deveria ser superada, considerando a importância da ressignificação dos saberes na formação dos professores.

A despeito da solidificação dos Estudos da Tradução e da oferta de cursos e programas que formam tradutores e pesquisadores (VENUTI, 2017), ainda parece prevalecer a conferência magistral no ensino de tradução e os avanços relativos às pesquisas sobre a formação de tradutores pouco têm influenciado a sala de aula de ensino de tradução, segundo os dados coletados e ora explicitados.

Por ainda inexistirem pesquisas sobre os saberes do professor de tradução, entendidos aqui como um construto que engloba a capacidade de gerenciamento e adoção de metodologias de ensino, embasamento teórico e prático concernente à disciplina que se ensina, uma disposição para se realizarem ações com propósitos pedagógicos relacionados a outras disciplinas do currículo, aos avanços da área e à capacidade de reflexão diária acerca da experiência profissional acumulada, é que se inseriu a proposta de continuação desta investigação. No tópico seguinte, são relatados os dados da segunda fase desta pesquisa envolvendo os mesmos docentes entrevistados.

\subsection{Resultados da segunda fase (2017): novos perfis e novas pedagogias dos docentes de tradução?}

Embora os achados da primeira fase tenham colocado em evidência a ausência de uma diretriz pedagógico-metodológica predominante para o ensino de tradução em cenário brasileiro, bem como perfis heterogêneos de docentes que concebem o saber profissional e mercadológico como o mais importante para o âmbito da sala de aula, perpetuando a conferência magistral como fórmula pedagógica, ressalta-se que a natureza dos saberes docentes é dinâmica, processual e complexa, podendo sofrer mudanças conforme passam-se os anos de experiência docente (TARDIF, 2002; PIMENTA, 2016; CHARLOT, 1997, 1999, 2000, 2001, 2005, 2009).

Assim, a segunda fase desta pesquisa buscou investigar, junto aos mesmos respondentes, como os docentes reconstroem o seu próprio itinerário formativo ao longo de suas carreiras e os modos como valorizam as pesquisas sobre o ensino na área, os diferentes contextos e processos de formação e de desenvolvimento profissional. Compreender como os professores se desenvolvem profissionalmente implica considerar os modos como eles aprendem (e aprenderam) a ensinar, em que medida as pesquisas sobre o ensino (de tradução) são incorporadas em seu fazer diário, bem como analisar os complexos fatores pessoais e contextuais que influenciam o 
seu crescimento profissional. Ao relerem as perguntas e o que responderam, em 2012, os entrevistados poderiam modificar suas respostas conforme conveniência, acrescentando, por exemplo, se seus procedimentos pedagógicos sofreram algum tipo de mudança, se sua opinião sobre o que é ser um bom professor de tradução mudou ou não, se seus saberes docentes agregaram outras necessidades.

Tratou-se, nessa etapa, de uma pesquisa qualitativo-longitudinal (FLORES, 2003), com amostragem dispersa (podendo ou não contar com o mesmo número de entrevistados), que, por meio de instrumentos não estruturados (questionários e entrevistas abertas realizadas pessoalmente, via software online de comunicação em áudio e vídeo e por correio eletrônico), buscou identificar como os professores de tradução (re)descrevem seu perfil e (re)definem seus saberes docentes após cinco anos da realização da pesquisa anteriormente respondida. A continuação desta pesquisa, em 2017, teve como objetivos secundários:

1. 1) Identificar se houve alteração no perfil dos docentes entrevistados em 2012, principalmente no que tange à sua formação acadêmica, área de atuação, pesquisa e aperfeiçoamento.

2. 2) Categorizar como os professores (re)definem seu modelo de saberes docentes e como esse se reverte em ações no fazer diário da sala de aula de prática de tradução.

3. 3) Analisar quais fatores se mostram determinantes para as mudanças, em caráter longitudinal, dos procedimentos pedagógico-metodológicos dos docentes entrevistados.

4. 4) Identificar quais procedimentos pedagógico-metodológicos foram incorporados à sala de aula pelos docentes ao longo de cinco anos, principalmente em virtude das pesquisas da área, analisando se persiste ou não a conferência magistral.

Huberman (1995 apud Giorgi et al., 2010) descreve as fases da carreira docente, que se estendem desde a entrada na profissão, passando por uma fase de estabilização; de diversificação; de questionar-se; da serenidade e distanciamento afetivo; do conservadorismo e lamentações; até o desinvestimento. O autor coloca que a fase "entrada na carreira" compreende os três primeiros anos de atuação docente e caracteriza-se pelos sentimentos de sobrevivência, relacionados ao "choque do real", e à descoberta. A "fase da estabilização" compreende o período de cinco a sete anos de serviço no magistério e caracteriza-se por um sentimento de competência pedagógica crescente, maior autoconfiança, satisfação profissional e gosto pelo ensino. A "fase da diversificação" envolve o período de oito a 15 
anos de atuação docente e caracteriza-se como uma etapa em que os sentimentos profissionais divergem, positiva ou negativamente, de acordo com os percursos vividos pelo docente. Quando da aplicação da primeira fase da pesquisa descrita no tópico anterior, a média de anos de experiência dos docentes era de 14 anos, sendo que o professor com maior experiência tinha 30 anos de profissão e os mais recémingressados uma média de quatro anos. Assim, de acordo com Huberman (1995 apud Giorgi et al., 2010), todos os docentes entrevistados, mesmo antes da aplicação da fase longitudinal, encontravam-se em fase de estabilização e diversificação da docência, o que sugere que suas proposições pedagógicas para a sala de aula de tradução ou se estabilizaram ainda mais ou sofreram alguma mudança em seu percurso.

Para além do caráter retrospectivo, esta nova fase da proposta de pesquisa incluiu o seguinte conjunto de perguntas feitas junto aos docentes: a formação contínua do professor de tradução é importante? Quais seriam os temas de seu maior interesse e em qual ordem de importância? Quais modalidades de ações formativas mais corresponderiam às suas necessidades cotidianas de sala de aula? Em sua opinião, quais conteúdos são mais difíceis e mais fáceis de serem trabalhados em sala de aula?

Após cinco anos de distância, foi possível estabelecer contato e obter respostas de dez dos 13 docentes que participaram da pesquisa em 2012, sendo cinco das instituições particulares e cinco das instituições públicas investigadas.

Com relação às mudanças realizadas nos questionários respondidos em 2012, um dos dez respondentes não alterou quaisquer informações nos Q1 e Q2, atestando que adota os mesmos procedimentos pedagógicos já explicitados, sendo que outro apenas alterou a idade e o tempo de experiência na docência.

Quando indagados sobre suas atividades como profissionais da tradução, os oito respondentes que modificaram o questionário relataram traduzir em paralelo às atividades de docência, atendendo principalmente ao âmbito acadêmico ao qual pertencem e a editoras. Os docentes relataram traduzir para áreas tais como a acadêmica, científica, técnica e juramentada. Um respondente afirmou estar traduzindo, em uma ação conjunta com seus alunos, na forma de orientação e supervisão, textos que serão utilizados pelos próprios alunos em sala de aula, com potencial de publicação em periódicos científicos da área.

Em comparação aos dados coletados em 2012, houve uma modificação no perfil dos docentes de instituições públicas, que passaram a traduzir mais. Os dados indicam que o fato de serem tradutores reconhecidos e poderem ter mais 
autoridade para corrigir seus alunos se fortaleceu, isto é, persiste a importância do saber profissional e mercadológico.

Em relação às informações acadêmico-profissionais, ainda concernentes ao Q1, apenas um dos oito respondentes relatou ter ingressado em um curso de graduação da área de psicologia, por estar insatisfeito com sua atuação docente, buscando obter maiores conhecimentos sobre as relações interpessoais em sala de aula.

Todos os professores relataram maior participação em eventos científicos da área de tradução e/ou linguística aplicada em nível nacional e internacional, tanto como ouvintes quanto apresentadores de trabalhos. Os respondentes também relataram maior participação em grupos de pesquisa e fóruns virtuais. Três respondentes relataram maior adesão a associações de tradutores. Um deles acrescentou que resolveu se filiar a uma associação em específico em razão das ações conjuntas e mais ativas desta com as universidades.

Quanto ao Q2, ao reavaliarem se os procedimentos pedagógicos adotados em sala sofreram alguma alteração, um deles afirmou solicitar aos alunos que complementem as traduções com reflexões sobre as estratégias e soluções utilizadas na tradução, e que destaquem pelo menos três momentos específicos em que necessitaram interromper a atividade para solucionar problemas tradutórios complexos. Dois docentes afirmaram ter transformado as disciplinas práticas em projetos de tradução mais duradouros, sendo que aos textos a serem traduzidos foram acrescentadas outras atividades preparatórias envolvendo público-alvo, função comunicativa do texto e outras informações relativas ao tipo e gênero textuais. O restante não relatou quaisquer alterações nos procedimentos pedagógicos adotados, ao contrário, reiteram que a rotina pedagógica consiste na apresentação do conteúdo do texto por meio de aulas expositivas, discussão sobre seu teor, leitura do texto com posterior orientação do professor quanto à tradução e busca por recursos e ferramentas que poderão auxiliar a tradução.

Com relação à forma como avaliam seus alunos, os oito respondentes não modificaram o que haviam explicitado na fase anterior da pesquisa, isto é, solicitam pseudônimos para que as traduções sejam avaliadas às cegas, paratextos para o registro de justificativas quanto às escolhas tradutórias feitas pelos alunos, feedback individual, chamada oral, tradução autocomentada para que o aluno tome ciência de suas escolhas, provas teóricas e práticas. Dois docentes acrescentaram, no entanto, que incentivam a autoavaliação, porém sem quaisquer detalhes acerca de sua implementação. Um respondente solicita que os alunos relacionem a teoria à prática dos textos traduzidos, portanto exigindo tal relação nas avaliações. Um 
respondente relatou seguir utilizando os mesmos critérios, porém busca incentivar que seus alunos submetam suas traduções à avaliação dos colegas de turma antes de serem entregues ao professor. Para um docente, a questão mais complicada é atribuir critérios para quaisquer tipos de tradução, que nunca têm um "gabarito a ser seguido" [sic].

Quanto aos fatores que mais influenciam/influenciaram as práticas pedagógicas adotadas em sala, os docentes não retiraram nada do que haviam respondido anteriormente, isto é, que foram e são influenciados por suas próprias atuações como tradutores ou pelos "bons professores" que os antecederam. Apenas um docente acrescentou, no entanto, que as oficinas, cursos, palestras e artigos publicados na área têm influenciado sua atuação como professor. Outro docente acrescentou que as novas ferramentas de tradução têm influenciado sua atuação, principalmente as que são gratuitas e de fácil acesso, fazendo-o agregar novos exercícios às práticas de tradução.

Para Flores (2010), contrariamente a outros profissionais, os professores já conhecem o contexto no qual exercem suas atividades: as escolas, as universidades, as salas de aula. $\mathrm{O}$ contato prolongado com a profissão, por meio da observação de outros professores, afeta o entendimento e a prática do ensino. Citando Lortie (1975), Flores (2010) argumenta que a "aprendizagem pela observação" associase ao resultado da experiência escolar ao longo de muitas horas, constituindo-se influência determinante na atuação do professor.

Os docentes também não modificaram o rol de saberes que delinearam para o professor de tradução na pesquisa de 2012. Reiterou-se o fato de que o professor tem que ter experiência como tradutor. No entanto, um docente acrescentou que o professor de tradução deve preocupar-se em avaliar o aluno de forma menos subjetiva. Outro ressaltou que apesar de sempre controlar as correções das traduções, tenta dar voz ao aluno. Com tal procedimento, esse docente relata ter percebido que os alunos têm dúvidas mais básicas do que ele esperava, buscando "dar abertura para os alunos se manifestarem sobre o andamento das aulas, suas expectativas e dificuldades" [sic]. Outro docente acrescentou que "continua achando que há pouco diálogo e interação entre os professores. Cada um acaba trilhando seu caminho sozinho" [sic].

Assim, os dados retrospectivos que emergem dessa coleta são importantes por considerarem a natureza dinâmica, processual e complexa da docência, sobretudo a partir da própria percepção e relato dos docentes no decorrer, neste caso, de cinco anos. Embora sem contar com uma investigação exaustiva das biografias pessoais dos docentes investigados, pode-se verificar que o aprimoramento da carreira do 
professor de tradução tem ocorrido de forma autônoma e assistemática, na própria sala de aula, sendo que as teorias e investigações relativas ao ensino de tradução pouco têm impactado na atuação do professor de tradução em cenário brasileiro. E muito embora a conferência magistral pareça ter perdido um pouco de sua força por parte de dois dos oito docentes, que mencionaram ter transformado as disciplinas práticas em projetos de tradução mais duradouros, essa "nova" pedagogia relatada ainda tem formato subjetivo e assistemático.

As disciplinas de prática da tradução que se vinculam a projetos tradutórios autênticos e mais duradouros (KIRALY, 2000), ou seja, que se valem de procedimentos pedagógicos construídos em equipe e levam em consideração o quê (tipo de texto), onde (cultura), quando (período e época), por que (função) e para quem (cliente e público-alvo) se traduz, podem ter um efeito positivo na formação de tradutores. Echeverri (2015) chama a atenção para o fato de que os contratantes dos serviços de tradução usualmente afirmam que os tradutores novatos são incapazes de trabalhar em equipe, não respeitam prazos de entrega dos projetos de tradução, não têm autocrítica, não sabem interagir com colegas, clientes, têm dificuldades de gerenciar suas próprias atividades de maneira autônoma e poucas habilidades na resolução de problemas tradutórios. Embora relatado por apenas dois docentes, os projetos de tradução mais duradouros parecem ir ao encontro de uma pedagogia mais condizente às dificuldades dos alunos.

A percepção dos docentes sobre o que é ser um bom professor de tradução também não se alterou de forma significativa. Os oito docentes não modificaram nada do que haviam relatado na primeira etapa da pesquisa, reiterando-se o fato de que o professor de tradução deve mostrar aos alunos quando suas escolhas são inadequadas, utilizando como modelo os tradutores consagrados para mostrar os prós e contras de uma boa tradução. Para eles, o professor ainda permanece no controle de todo o processo de aprendizagem. Dois docentes, no entanto, acrescentaram que o professor de tradução deve ser capaz de desenvolver nos alunos a competência tradutória, concebendo o processo de tradução como algo complexo.

A maioria dos respondentes prevê a centralização do processo de ensino e aprendizagem, responsabilizando-se pela avaliação das traduções. O bom professor passa a ser aquele que, novamente, transmite um conteúdo, projetando sua posição privilegiada. Nas palavras de Arrojo (1993), o professor de tradução deve tentar transformar sua prática educacional numa reflexão permanentemente crítica sobre o status de qualquer texto original, sobre a forma pela qual seu significado pode ser produzido e privilegiado dentro da relação transferencial em que nasce e dentro de 
certa comunidade cultural e, finalmente, sobre a intervenção inevitável do tradutor nesse estado de coisas.

Os dados apresentados a seguir revelam as percepções dos professores com relação ao já citado conjunto de perguntas: a formação contínua do professor de tradução é importante? Quais seriam os temas de seu interesse e em que ordem de importância? Quais modalidades de ações formativas (ou cursos de formação contínua) mais corresponderiam às suas necessidades cotidianas? Quais conteúdos você considera mais difíceis e mais fáceis de serem trabalhados em sala de aula?

Como mencionado, foi possível estabelecer contato com dez dos 13 professores entrevistados em 2012. Nessa etapa, o respondente que não modificou o Q1 e Q2, e o respondente que apenas alterou a idade e o tempo de experiência na docência participaram da pesquisa, respondendo o questionário prospectivo.

Com relação à primeira pergunta, verifica-se que $100 \%$ dos respondentes manifestaram interesse pela formação contínua, considerando-a essencial, o que revela o compromisso dos docentes com o seu processo de desenvolvimento profissional e de seus alunos.

Quanto aos assuntos de interesse para fins de formação contínua, nove dos dez professores mencionaram que gostariam de aprimorar seus conhecimentos no tocante às novas tecnologias, principalmente com relação às ferramentas de auxílio à tradução, como os sistemas de memória de tradução, tradução automática e pósedição. Três respondentes destacaram, além disso, a necessidade de aprimoramento na prática da tradução audiovisual. Quanto ao interesse em aprimorar-se didaticamente, quatro docentes referiram-se à necessidade de cursos de formação contínua que tratem especificamente da elaboração eficaz de materiais.

Por um lado, essas respostas revelam as dificuldades reais que permeiam a sala de aula de ensino de tradução, como a escolha de materiais a serem traduzidos, nível de dificuldade, articulação entre teoria e prática e a inserção tecnológica. De outro lado, sob a perspectiva da racionalidade técnica, existe uma expectativa dos docentes investigados de seguirem materiais prontos e soluções imediatas. Um respondente destacou que deseja que as oficinas em congressos da área sejam mais aprofundadas, pois são normalmente superficiais e para iniciantes e não agregam valor à prática docente.

Feiman-Nesser (2001) explica que esse tipo de percepção de professores tem relação com a forma convencional com que a academia e as instituições buscam aprimorar a prática docente. Para a autora, tradicionalmente, o desenvolvimento do corpo docente se dá de maneira ineficaz. Os professores participam de congressos nos quais especialistas externos dão palestras inspiradoras, apresentam os resultados 
mais recentes de pesquisas e introduzem novas técnicas e estratégias. Eles têm pouco a dizer sobre a pedagogia em si, sobre as interações e problemas de sala de aula. Para a autora, "os professores podem voltar para casa com uma ideia nova, mas o formato desses congressos torna improvável que a prática dos professores sofra alguma alteração significativa ${ }^{\prime \prime}$ (FEIMAN-NESSER, 2001, p. 1041, nossa tradução).

Quando indagados quais conteúdos são mais fáceis e difíceis de serem trabalhados em sala, $50 \%$ dos participantes da pesquisa consideram os conteúdos de prática de tradução mais difíceis de serem ensinados, o que sugere que a formação que o professor recebe nos programas de mestrado e doutorado em Tradução parece suprir formas de ensino da teoria, em detrimento de sua articulação com a prática. Com relação ao restante dos respondentes, 30\% mencionaram que ambos os conteúdos são difíceis de serem ensinados e outros 20\% mencionaram que depende da experiência do professor.

Com relação aos dados prospectivos, de um lado, o que parece causar dificuldade aos docentes é trabalhar com a prática da tradução mediada pelas novas tecnologias, uma referência que os professores, no caso dos participantes desta pesquisa, não trazem consigo, já que têm perfis heterogêneos, se formaram em áreas diversas e em épocas em que os sistemas de memória de tradução e outras tecnologias da tradução não pareciam ser imperativas ou objeto de estudo e pesquisa. De fato, os dados mostram o anseio por aprimorar a prática para melhor atender os alunos e propiciar o diálogo com o mercado de trabalho. Por outro lado, ao elencarem os conteúdos mais fáceis e mais difíceis de serem ministrados, nenhum dos respondentes apontou a articulação entre teoria e prática, o que pode indicar, mais uma vez, a perpetuação da dissociação entre elas (ARROJO, 1993, 1998; DARIN, 2001).

\section{ENCAMINHAMENTOS FINAIS}

Para resumir, a presente pesquisa, desmembrada em duas fases, teve como proposta, inicialmente implementada em 2012, identificar o perfil de docentes de tradução em cenário brasileiro e suas percepções sobre seus próprios saberes docentes; e, em fase posterior, que ocorreu após um intervalo de cinco anos, examinar se a conferência magistral persiste ou se ocorreram mudanças nas ações

9. Teachers may go home with a new idea, but the design of these sessions makes it unlikely that teacher's practice will change in any significant way. 
pedagógicas em sala de aula e o que se mostra mais difícil e mais fácil de ser trabalhado com os alunos.

$\mathrm{Na}$ busca por ouvir o que têm a dizer os professores de tradução sobre as salas de aulas onde atuam, foi possível perceber o caráter complexo da docência em tradução, e com isso subsidiar possíveis discussões acerca das necessidades reais da sala de aula de ensino de tradução.

Primeiramente, faz-se pertinente salientar que, em decorrência desses resultados, se reconhece a carência de trabalhos investigativos que consolidem e socializem a discussão sobre as ações concretas (e também almejadas) de professores de tradução. Embora existam muitas teorias da tradução que se voltem ao ensino e à didática, a sala de aula continua sendo um espaço complexo onde convivem diversos indivíduos com personalidades e experiências singulares (PIMENTA, 2016), gerando, nas palavras de Darin (2001) desafios, reflexões, teorias e discursos que nos incitam a abrir novas frentes de estudo e a renovar o olhar diante do suposto conhecido.

Em segundo lugar, confirma-se a hipótese de que a pedagogia vigente no ensino da prática da tradução, em se tratando do universo investigado, parece ainda se pautar na conferência magistral, ou seja, as atividades realizadas pelos alunos contam muito pouco na cena pedagógica, pois, em última instância, eles deverão obedecer às soluções de tradução propostas pelo professor. Nesse prisma, persiste a ideia de equiparar o desempenho profissional do professor ao objetivo final da formação dos futuros tradutores, assim como nos achados de Darin (2001). Embora expressos por um número reduzido de docentes, os dados restrospectivos da pesquisa longitudinal revelaram algumas mudanças nos procedimentos pedagógicos adotados, rumo a uma pedagogia que acolhe a participação dos alunos e o desenvolvimento de suas competências tradutórias em projetos de tradução mais duradouros.

Em terceiro lugar, a despeito do fato de a pedagogia da tradução se mostrar assistemática, inconsistente e pautada na conferência magistral, os docentes entrevistados são produtores de conhecimento e se esforçam para encontrar subsídios pedagógicos, os quais, possivelmente, não lhes foram formalmente apresentados em cursos de mestrado ou doutorado, por eventos acadêmico-profissionais da área ou por ações de formação contínua em suas próprias instituições.

Um quarto ponto de discussão que pode ser elucidado por meio dos dados coletados diz respeito à forma como os professores definem seus saberes para além da dimensão profissional e mercadológica, com destaque à dimensão social, em que os respondentes mencionam que o professor de tradução deve saber ouvir, 
saber explicar e transmitir sua experiência aos alunos, saber aceitar as diferenças, ter carisma, ter boa convivência, perceber as limitações dos alunos e saber saná-las na hora certa, dentre outros. Nessas respostas, observa-se que os professores, como menciona Pimenta (1996), atuam como mediadores sociais, conferindo à prática docente os seus valores, modo de situar-se no mundo e percepção de que os alunos também têm suas próprias histórias de vida.

Com relação aos dados prospectivos da pesquisa longitudinal, não há dúvidas de que a articulação entre teoria e prática continua sendo de difícil implementação. Conforme já mencionado, ao elencarem os conteúdos mais difíceis e mais fáceis de serem trabalhados em sala, os professores expressam dificuldades em lidar com ambas de forma conjunta. Ainda, ao revelarem o que realmente os desafia na pedagogia da tradução, os professores relatam suas dificuldades em responder às demandas mercado atual da tradução, que se encontra totalmente assistido por sistemas computacionais (BOWKER, 2015), o que revela também que os professores estão trilhando sozinhos seus princípios pedagógicos, possivelmente em razão da falta de diálogo entre a indústria da língua e da tradução e os cursos de formação de tradutores (SIN-WAI, 2015). Nesse prisma, os seus saberes docentes encontramse fragmentados e o professor enfrenta vários desafios, seja na articulação teoria e prática, seja no manejo das tecnologias, seja com relação à falta de diálogo entre docentes e apoio institucional, ou no estabelecimento criterioso de princípios pedagógicos.

Por fim, ouvir o que os professores têm a dizer não é algo que se encontre com frequência nas publicações dos Estudos da Tradução. Por isso, os desafios metodológicos são imensos. Relata-se o fato de que enfrentar as dificuldades de uma pesquisa de cunho qualitativo-exploratório e longitudinal, que demanda o consentimento dos docentes e a permissão de suas instituições de origem para a aplicação dos questionários, bem como o retorno desses e a busca pelos mesmos respondentes após cinco anos, pareceu necessário para sustentar a ideia de que a investigação sobre o ensino da tradução perpassa não apenas pela discussão do que deve ser idealmente ensinado (sua didática), mas também pelas ações dos professores (pelas pedagogias vigentes), que são atores de uma experiência acumulada que explica e detalha a realidade brasileira sobre a formação de tradutores.

\section{$\overline{\text { REFERÊNCIAS }}$}

ALVES, F. (1997). A formação de tradutores a partir de uma abordagem cognitiva: reflexões de um projeto de ensino. TradTerm, v. 4, nº 2, pp. 19-40. 
ALVES, F. (2003). Tradução, cognição e contextualização: triangulando a interface processo-produto no desempenho de tradutores novatos. DELTA. Documentação de Estudos em Linguística Teórica e Aplicada, v. 19, pp. 71-108.

ARROJO, R. (1993). Tradução, desconstrução e psicanálise. Rio de Janeiro: Imago Editora.

ARROJO, R. (1998). The revision of the traditional gap between theory \& practice and the empowerment of translation in postmodern times. The Translator - Studies in Intercultural Communication, v. 4, $\mathrm{n}^{\mathrm{O}} 1$, pp. 25-49.

ASSUINÇÃO, M. M. (1996). Magistério primário e cotidiano escolar. Campinas: Autores Associados.

BOWKER, L. (2015). Computer-aided translation: translator training. In: SIN-WAI, C. (org.). The Routledge encyclopedia of translation technology. Londres e Nova York: Routledge, 2015. pp.88-104.

BOWKER, L. (2005). Productivity vs quality: a pilot study on the impact of translation memory systems. Localisation Focus, v. 4, n 1 , pp. 13-20.

CARVALHO, M. P. (1999). No coração da sala de aula: gênero e trabalho docente nas séries iniciais. São Paulo: Xamã.

COLINA, S. (2003). Teaching translation: from research to the classroom. Boston: McGraw Hill, 2003.

COLINA, S. (2015). Ensino de tradução: da pesquisa à sala de aula. Diretrizes para professores, trad. Marileide Dias Esqueda, Paula Godoi Arbex, Sandra Aparecida Faria de Almeida, Silvana Maria de Jesus e Stéfano Paschoal. Uberlândia: EDUFU, 2015.

CHARLOT, B. (1997). Nouveaux publics, nouveaux rapports au savoir: nouvelles fonctions de l'université? Actes du colloque de l'Association des conseillers d'orientation psychologues de France. Le défi de la réussite. Paris: Sorbonne, pp. 41-50.

CHARLOT, B. (1999). Rapport au savoir en milieu populaire: une recherche dans les lycées professionnels de banlieue. Paris: Anthropos.

CHARLOT, B. (2000) Da relação com o saber: elementos para uma teoria, trad. Bruno Magne. Porto Alegre: Artes Médicas Sul.

CHARLOT, B. (org.). (2001). Os jovens e o saber: perspectivas mundiais. Porto Alegre: Artes Médicas. 
CHARLOT, B. (org.). (2005). Relação com o saber, formação dos professores e globalização: questões para a educação hoje. Porto Alegre: Artmed.

CHARLOT, B. (2009). A relação com o saber nos meios populares: uma investigação nos liceus profissionais de subúrbio. trad. Cataria Matos. Porto: Livpsic.

DARIN, L. C. M. (2001). Exame crítico do ensino da tradução em nível universitário. Contexturas, $\mathrm{n}^{\mathrm{O}} 5$, pp. 59-78.

DELISLE, J. (1993). La traduction raisonnée: manuel d'initiation à la traduction professionnelle de l'anglais vers le français. Ottawa: Ottawa University Press.

ECHEVERRI, Á. (2015). El alumno de traducción centro de la formación: conócete a tí mismo y... Belas Infiéis, v. 4, nº 2, pp. 9-35.

ECHEVERRI, Á. (2008). Énième plaidoyer pour l'innovation dans les cours pratiques de traduction. Préalables à l'innovation? TTR. Montréal. 21 (1), pp. 65-98.

ESQUEDA, M. D.; DE OLIVEIRA, K. I. (2013) Crenças e concepções do tradutor em formação. Tradução em Revista, v. 14, nº 1, pp. 138-166.

FEIMAN-NEMSER, S. (2001) From preparation to practice: Designing a continuum to strengthen and sustain teaching. Teachers College Record, 103 (6), pp. 1013-1055.

FLORES, M. A. (2003). Investigar (com) os professores: reflexões sobre uma pesquisa longitudinal. Perspectiva, Florianópolis, v. 21, nº 2, pp. 391-412.

GIORGI, C. A. G. et al. (2010). Necessidades formativas de professores de redes municipais: contribuição para a formação de professores crítico/reflexivos. $1^{\text {a }}$ Ed. São Paulo: Cultura Acadêmica/Editora UNESP.

GONÇALVES, J. L.V. R. (2015). Repensando o desenvolvimento da competência tradutória e suas implicações para a formação do tradutor. Revista Graphos, vol. 17, pp. 114-130.

GONÇALVES, J. L. V. R.; MACHADO, I. (2006). Um panorama do ensino de tradução e a busca da competência do tradutor. Cadernos de Tradução, Florianópolis, v. 1, n ${ }^{\circ} 17$, pp. $45-69$.

GUERINI, A.; TORRES, M-H.; COSTA, W. C. (org.). (2013). Os Estudos da Tradução no Brasil nos séculos XX e XXI. Tubarão: Copiart. 
HUBERMAN, M. (1995). O ciclo de vida profissional dos professores. In: NÓVOA, A (org.). Vidas de professores. $2^{\text {a }}$ Ed. Porto: LDA, pp. 31-59.

HURTADO ALBIR, A. (1999). Enseñar a traducir: metodología en la formación de traductores e intérpretes. Madrid: Edelsa.

KELLY, D. (1995) A bandbook for translator trainers: a guide to reflective practice. Manchester, UK: St. Jerome.

KIRALY, D. (2016). De pressupostos sobre o conhecimento e a aprendizagem à práxis na formação do tradutor, trad. Patrícia Rodrigues Costa. Belas Infiéis, v. 5, nº 1, pp. 227-249.

KIRALY, D. (2000). A social constructivist approach to translator education: empowerment from theory to practice. Manchester: St. Jerome.

KIRALY, D. (1995). Patbways to translation: Pedagogy and process. Kent, Ohio: Kent State University Press.

LADMIRAL, J-R. (1979) Traduire: Théorèmes pour la traduction. Paris: Petite Bibliothèque Payot.

LORTIE, D. C. (1975). Schoolteacher: A sociological study. Chicago: University of Chicago Press.

NORD, C. (1991). Text analysis in translation: theory, methodology, and didactic application of a model for translation-oriented text analysis. Amsterdã: Rodopi.

PAGANO, A.; VASCONCELlOS, M. L. (2006) Apresentação. Cadernos de Tradução, Florianópolis, v. 1, nº 17, pp. 9-17.

PAGANO, A.; VASCONCELLOS, M. L. (2003). Estudos da tradução no Brasil: reflexões sobre teses e dissertações elaboradas por pesquisadores brasileiros nas décadas de 1980 e 1990. Delta, v. 19, pp. 1-25.

PIMENTA, S. G. (2016). Saberes Pedagógicos e atividade docente. $8^{a}$ Ed. São Paulo: Cortez Editora.

PIMENTA, S. G. (1996). Formação de professores: saberes da docência e identidade do professor. Revista da Faculdade de Educação, v. 22, nº 2, pp. 72-89.

PYM, A. (2003). Redefining translation competence in an electronic age in defense of a minimalist approach. Meta: Translators' Journal, Montreal, v. 48, nº 4, pp. 481-49. 
ROBINSON, D. (1997). Becoming a translator: an accelerated course. $1^{\text {a }}$ Ed. Nova York: Routledge, 1997.

ROBINSON, D. (2002). Construindo o tradutor, trad. Jussara Simões. Bauru: EDUSC.

RODRIGUES, C. C. (2013). Os Estudos da Tradução no Brasil nos programas brasileiros de pós-graduação. In: GUERINI, A.; TORRES, M-H.; COSTA, W. C. (org.). Os Estudos da Tradução no Brasil nos séculos XX e XXI. Tubarão: Copiart.

SIN-WAI, C. (org.). (2015). The Routledge encyclopedia of translation technology. Londres e Nova York: Routledge.

TANURI, L. M. (2000). História da Formação de professores. Revista Brasileira de Educação: 500 anos de educação escolar, n⿳0 14, pp. 61-88.

TARDIF, M. (2002). Saberes docentes e formação profissional. $3^{\text {a }}$ Ed. Petrópolis: Vozes.

TIRKKONEN-CONDIT, S. (1989). Professional versus non-professional translation: a think-aloud protocol study. In: SÉGUINOT, C. (ed.). The translation process. Toronto: HG Publications, 1989.

TIRKKONEN-CONDIT, S. (ed.). Empirical research in translation and intercultural studies. Tü bingen: Gü nther Narr, 1991.

VENUTI, L. (ed.). (2017). Translation Teaching: programs, courses, pedagogies. New York, NY: Routledge.

VYGOTSKY, L. S. (1998). A formação social da mente, trad. José Cipolla Neto, Luis Silveira Menna Barreto e Solange Castro Afeche. São Paulo: Martins Fontes.

Recebido: 8/03/2018

Aceito: 18/07/2018 